
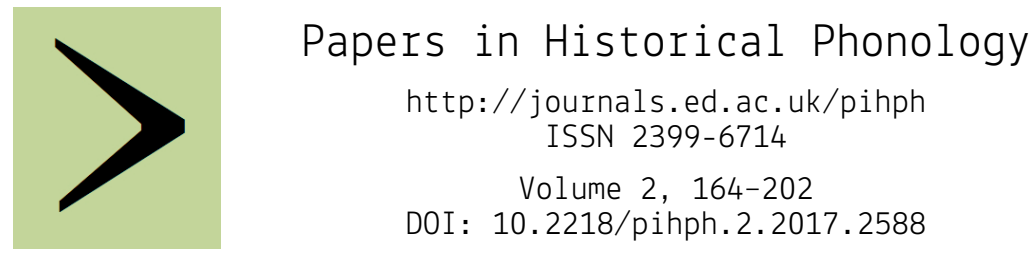

DOI: $10.2218 /$ pihph.2.2017.2588

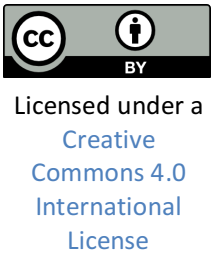

\title{
Breaking the symmetry of geminates in diachrony and synchrony
}

\author{
Michela RuSSO \\ University of Lyon 3, Jean Moulin \& UMR SFL 7023 CNRS-Paris 8 \\ SHANTI ULFSBJORNINN \\ University of Lyon \& UCL - University of London
}

\begin{abstract}
Autosegmentalism invariably represents geminates in a symmetrical oneto-many relationship - as feature bundles or root nodes attached to two structural units: x-slots, moras, or C-slots. This symmetry, however, is often not reflected in their diachronic origin. For instance, in Blevins' (2008) Type 1 pathway, only the second $\mathrm{C}$ of a consonant cluster (CC) ever determines the geminate: $\mathrm{C}_{\mathrm{x}} \mathrm{C}_{\mathrm{y}}>\mathrm{C}_{\mathrm{y}} \mathrm{C}_{\mathrm{y}},{ }^{*} \mathrm{C}_{\mathrm{x}} \mathrm{C}_{\mathrm{x}}$ (e.g. Latin $>$ Italian). Moreover, although most synchronic processes identify geminates as symmetrical, there is an exception: geminate integrity. Unlike CCs and long vowels (LVs), geminates never 'break' by epenthesis: ${ }^{*} \mathrm{C}_{\mathrm{y}} \mathrm{C}_{\mathrm{y}}>\mathrm{C}_{\mathrm{y}} \mathrm{VC}$. We propose that this is central to understanding the true nature of geminates, and present analyses in two frameworks. The first is 'control by contiguity', which uses head-dependent 'control chains' (Russo 2013). A control relation applies between a specified and an unspecified position: $\emptyset$-C. Inalterability and integrity result from the asymmetry of the geminate's positions. The second is based on Strict CV. This restricts a geminate's melody to one of its two skeletal positions. Unlike CC and LVs, geminates do not involve a 'trapped' empty $\mathrm{V}$ position that could host epenthesis and cause breaking; the difference between LVs and geminates follows from framework-internal forces and suggests that melodic branching always requires licensing. These two approaches share the insight that the representation of geminates is not symmetrical, like that of long vowels.
\end{abstract}

\section{Introduction}

\subsection{Geminates and positions}

From a synchronic point of view, geminates behave in the way one would expect if they were segments symmetrically distributed across two syllabic positions (Hayes 1989, Kenstowicz 1994, Davis 2011). 
The autosegmental analysis of geminates has been more or less unchallenged since Hayes (1989) introduced the 'flopped' structure. In this representational model, a single bundle of features or a consonantal segment is shared across two heterosyllabic positions, as in (1).

(1) Flopped structure of a geminate (Hayes 1989)

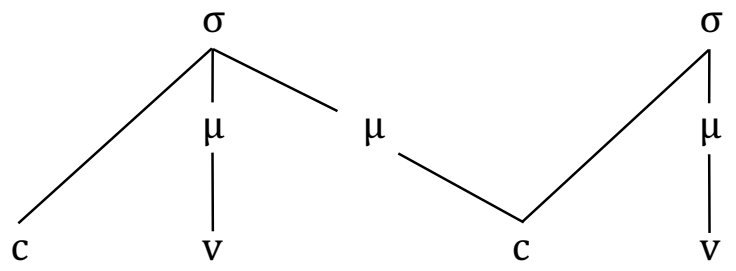

The synchronic phonology of languages like Italian furnishes clear evidence that the synchronic structural representation of geminates involves two heterosyllabic positions. Italian has a strict condition on the number of skeletal positions in a stressed rime/syllable called: metrical lengthening (Hayes 1995). All stressed rimes must contain two positions. Therefore, monopositional vowels cannot satisfy metrical lengthening on their own. In Tuscan Italian, this results in vowel lengthening (2a). However, if the monopositional vowel is joined by the first position of a heterosyllabic cluster (of the 'RT' type), the vowel can remain monopositional (there is no lengthening) (2b). Clusters of the 'TR' type cannot satisfy this requirement and stressed vowels before them are obliged to lengthen (2c). The form in (2d) shows what happens when a stressed vowel is followed by an R.TR cluster. As we would expect, the vowel does not have to lengthen.

As we have established, metrical lengthening offers a very clear diagnostic for heterosyllabicity and in this test, geminates behave exactly like RT clusters (and not like TR clusters or singleton consonants) (2e) - they are preceded by monopositional short vowels.

(2) Italian metrical lengthening with near minimal pairs
(a) *CV́CV
(i) *fáto
fa:to
'faith'
(b) CV́RTV
(i) málta
'Malta'
(ii) márte
'Mars'
(c) *CV́TRV
(i) *métro
mé:tro
'metro'
(d) CV́RTRV
(i) déntro
'inside'
(e) CV́GV
(i) fát:o
'fact'
(ii) fétra
'slice' 
A diachronic development that clearly shows the bipositionality of geminates comes from the shift of Sanskrit to Pāli. As we see in (3), compensatory gemination makes up for the loss of $\mathrm{C} 1$ in a consonant cluster.

(3) Pāli gemination (Zec 1994)

$\begin{array}{lll}\text { Sanskrit } & \text { Pāli } & \\ \text { mugda } & \text { mud:a } & \text { 'bean' } \\ \text { dharma } & \text { dham:a } & \text { 'righteousness' } \\ \text { sarpa } & \text { sap:a } & \text { 'snake' } \\ \text { karna } & \text { kan:a } & \text { 'ear' }\end{array}$

Tests like the one above prove that the structural description of geminates involves two positions of skeletal/syllable structure, and the results are entirely consistent with the 'flopped' representation in (1).

However, it is important to note that a test such as this does not demonstrate how the features of a geminate are organised. Rather, it is assumed (in analogy to long vowels), that a single root node is symmetrically linked to multiple positions. Though this seems perfectly reasonable, this assumption leads to at least one problem and one misprediction. The argument principally comes from diachronic language change. Crucially, geminates appear to be qualitatively different to both consonant clusters (CCs) (including partial geminates) and long vowels when it comes to 'inalterability'. CCs and VVs can be shown to undergo breaking but geminates never do.

\subsection{Clusters and geminate breakability}

At least since Kenstowicz \& Pyle (1973), Guerssel $(1977,1978)$ and Steriade (1982/1990), we have known that geminates differ from heterosyllabic consonant clusters (C.C), though we know that the two resemble each other closely in terms of phonological behaviour. This difference has come to be known as geminate integrity and refers to the fact that monomorphemic, non-derived geminate consonants appear to be universally resistant to the kinds of epenthetic events that so often split up consonant clusters (both CC and C.C).

Davis \& Raghib (2014) discuss one such case from Hadhrami Arabic. As shown in (4), C.C clusters are subject to being broken by epenthesis, while geminates $(G)$ are not.

(4) Geminate integrity (Davis \& Raghib 2014)
(a) RT /gird/ [girid]
(b) NT /bint/ [binit]
'monkey'
(c) G /rab:/ [rab:] *[rabib] 'lord' 
As far as we know, there is not a single compelling and observed case of a language or dialect where underived monomorphemic geminates have de-geminated through breaking: $\mathrm{C}_{\mathrm{y}} \mathrm{C}_{\mathrm{y}}>\mathrm{C}_{\mathrm{y}} \mathrm{VC}_{\mathrm{y}}=$ ap:a $>$ apipa.

The absence of such a process is striking given that geminates are common in the world's languages and consonant cluster reductions and changes in syllable quantity are also extremely frequent. In fact, every language whose history is known well enough can be shown to have undergone the development and simplification of consonant clusters.

The closest thing to an example of geminate breaking comes from the cases where geminates originate from vowel loss: $C_{x} V C_{x}>C_{x} C_{x}$ (Blevins 2004). In these languages rule reversal can make a vowel deletion pattern into a vowel insertion pattern, as Blevins explains. However, as far as we are concerned, these are not true geminates. The language did not diachronically stabilise a geminate pattern and then have it broken up by epenthesis, rather a vowel deletion process was reinterpreted as vowel epenthesis between adjacent identical Cs. Structures like those shown in (5) are not true geminates, but merely 'bogus geminates': two root nodes/segments each specified for the same consonant. Bogus geminates have also been reported in the classic phonological literature. Their representation is identical to that of the 'false geminates' of Tigrinya (Kenstowicz 1994). These are distinguished by their left part (C1), which undergoes spirantisation: /mərak $+\mathrm{ka} / \rightarrow$ [məraxka] 'your calf'.

(5) Bogus or fake geminate (in Strict CV notation)

$$
\begin{array}{ccccccc} 
& \mathrm{C} & \mathrm{V} & \mathrm{C} & \mathrm{V} & \mathrm{C} & \mathrm{V} \\
& \mathrm{l} & \mathrm{l} & \mathrm{l} & & \mathrm{l} & \text { l } \\
\ldots & \mathrm{r} & \mathrm{a} & \mathrm{k} & & \mathrm{k} & \mathrm{a}
\end{array}
$$

Hayes (1986) explains geminate integrity as a consequence of a geminate's representation and a UG prohibition on line crossing. The argument goes that geminates have a 'length representation', therefore any epenthesis into the geminate would necessarily involve line crossing as in (6). Crucially, this condition does not hold in RT consonant clusters.

(6) Geminate integrity and line crossing
(a) $\mathrm{rt}>$ rit $\left(\mathrm{C}_{\mathrm{x}} \mathrm{C}_{\mathrm{y}}>\mathrm{C}_{\mathrm{x}} \mathrm{VC}_{\mathrm{y}}\right)$
(b) $*_{\mathrm{t}}>$ tit $\left(\mathrm{C}_{\mathrm{y}} \mathrm{C}_{\mathrm{y}}{ }^{*}>\mathrm{C}_{\mathrm{y}} \mathrm{VC}_{\mathrm{y}}\right)$
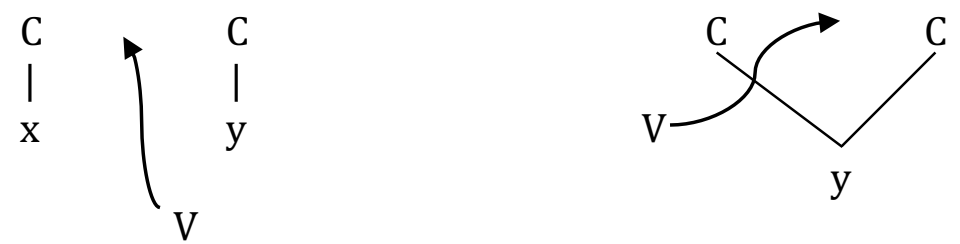
This argument has been compelling and has helped motivate the symmetric-length-approach to geminates that is essentially ubiquitous in phonological theory. However, this account of geminate integrity is almost certainly wrong.

Hayes' (1986) theory of geminate integrity predicts that long vowels should show comparable integrity to geminates. He therefore falsely predicts the effect of long vowel integrity (see Blevins 2004 who makes the same point). This is schematically shown in (7).

(7) Predicted Long Vowel (LV) integrity

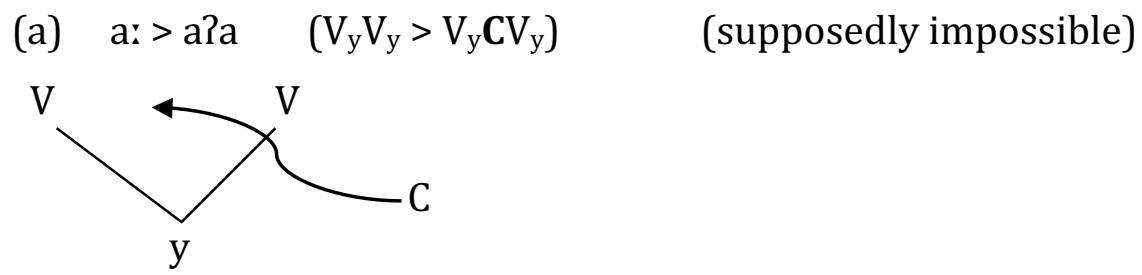

There are, however, at least two unrelated languages where long vowels $\left(\mathrm{V}_{\mathrm{y}} \mathrm{V}_{\mathrm{y}}\right)$ optionally alternate between a 'broken' form $\left(\mathrm{V}_{\mathrm{y}} \mathrm{CV}_{\mathrm{y}}\right)$. In Arbore, an Eastern Cushitic language of Eastern Africa, long vowels are optionally broken by the consonant ' $h$ ' or '?': [zerhse] = [zehese] 'I cause to melt' and [ke:?te] = [ke?ete] 'she planted' (Hayward 1984). Elsewhere, in Marshallese, an Oceanic language of Micronesia, long vowels are also optionally interpolated by [j, w, h] (Bender 1968, Willson 2003).

This raises the following question: if geminate inalterability is not explained by the prohibition on line crossing, then what is it caused by? Blevins' (2004) answer is 'nothing' - at least in synchrony or the phonological component. For her geminate integrity is a substantive diachronic consequence of a geminate's stronger phonetic cues. This is an explanation that extends to the strength of homorganic heterosyllabic consonant clusters (C.C).

It is beyond doubt that this cue-strength hypothesis has a place in explaining the relationship between phonetics and diachrony. It is certainly true that shared features convey both strength and nondivisibility to consonant clusters, and homorganicity, in particular, adds resistance to epenthesis and lenition (Honeybone 2005). However, the cue-strength analysis is not a complete explanation for geminate integrity as it does not account for the categorical nature of the effect.

Geminates and homorganic NT sequences do not appear to be on a gradient scale when it comes to integrity. It is not the case that there are fewer cases of geminate breaking $\left(\mathrm{C}_{\mathrm{x}} \mathrm{C}_{\mathrm{x}}>\mathrm{C}_{\mathrm{x}} \mathrm{VC}_{\mathrm{x}}\right)$ when compared with homorganic N.C breaking (N.C > NV.C). 
Outside of the cases of Blevins' (2004) 'rule reversal' (as discussed above) there are simply no known cases of monomorphemic underived geminates being broken by epenthesis. Conversely, as we saw in (3), there are cases of homorganic N.C breaking by epenthesis. One example is from Hadhrami Arabic in (4): /gird/ $\rightarrow$ [girid] 'monkey', /bint/ $\rightarrow$ [binit] 'girl' (Davis \& Raghib 2014). In this data, we see a homorganic N.C cluster, which ought to be the strongest of all consonant clusters (cf. Ulfsbjorninn \& Lahrouchi 2016), breaking by epenthesis.

With regard to breaking by epenthesis, geminates and consonant clusters do not form a natural class. Conversely, different types of C.C are on a strength scale. The sonorant-obstruent clusters (R.T) are weaker than homorganic nasal-obstruent clusters (N.T): RT < NT. This difference in strength is well modelled by gestural overlap. Geminates, on the other hand, are not relatively stronger, they appear to be unbreakable by epenthesis.

In the remainder of this article, the diachronic (and synchronic) absence of geminate breaking will be analysed based on the phonological asymmetry of a geminate's two positions: $\mathrm{C}_{1}$ and $\mathrm{C}_{2}$. Before that (in section 2), we consider a point that we show to be related: the asymmetry of geminates is intimately connected to their diachronic development. We demonstrate this in some detail in aspects of the transition from Latin to Italian. With this empirical background in mind, we explore two (related) approaches to explain anew the behaviour of geminates. In much of sections 2 and 3, we set out an explanation based on the theory of control by contiguity. In section 4, we set out an explanation based on the Strict CV framework. Section 5 concludes.

\section{The diachrony of geminates}

Geminates have a double origin: they are either lexical or they result from assimilatory rules, synchronic or diachronic. Even when derived, geminates are different to identical adjacent segments that result from the juxtaposition of morphemes (as in black + kite [blàk:áit] 'black kite', un + necessary [ $\Lambda$ n:ćsəs.ii] 'unnecessary').

To consider true geminates, taking Latin as an example, we see that many geminates were derived diachronically by the proclisis of prepositional forms, such as those in (8).

\section{(8) Latin proclitics: $\breve{\mathrm{A} D}, \mathrm{IN}, \mathrm{D} \overline{\mathrm{E}}+\mathrm{AB} \ldots$ (Italian $a$, in, $d a$ respectively)}

Forms such as ĂD or SUB can be considered proclitics that lexically project a consonant that forms a branching rime: $\breve{A} \underline{D}$ or SUB. These are merged with stems in the following schema: $W_{1}+W_{2}$. Already by the 
Late Latin period, all $\mathrm{W}_{1}$ proclitics (AD, ET, NEC, PLUS, TRES, SUB, QUID, SUM, SIS, EST, SUNT etc.) had undergone diachronic despecification of their final consonants, so that their underlying representations were as shown (for SUB) in (9).

(9) Despecification of final Cs in Latin (see Russo 2014) ${ }^{1}$

Lat. SUB $/ \mathrm{su} \emptyset_{\mathrm{c}} / \quad=\quad \mathrm{W}_{1}$

(a) su die $=s u b$, with omission of $-b$ in CIL VIII. 457 IV c. chr. (Provinciae Tripolitana and Byzacena)

(b) su d(ie) CIL X.3316 chr. (Puteoli), SVD (« lege su[b] d(ie)”, ed.) R II 4418c VI c.

(c) sud die CIL V.8280 = sub die

(d) suc cura CIL VI.9502 = sub cura ${ }^{2}$

Autosegmentally, this operates by a despecification of the final consonant of $\mathrm{W}_{1}$ resulting in an opaque, unspecified position: [+cons], as in (10). This despecified position $\left(\varnothing_{c}\right)$ results in gemination of a following consonant (as is shown in (9)).

(10) Unspecified position

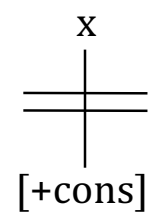

The diagram in (10) represents a diachronic change. The different forms of proclitics can be explained phonologically with the inclusion of this underspecified 'zero C': $\left(\emptyset_{c}\right)$. This gives the proclitics IN and AD the following underlying structure: $/ \mathrm{i} \emptyset_{\mathrm{c}} /$ and $/ \mathrm{a} \emptyset_{\mathrm{c}} /$. This despecified position, which is typical of proclitics, results in the gemination of a following consonant, as shown in (11).

(11) Gemination in $W_{1} W_{2}$ schema

$\begin{array}{lll}\text { Input: } & \text { su } / \emptyset_{\mathrm{c}} / \text { die } & \text { su } / \emptyset_{\mathrm{c}} / \text { cura } \\ \text { Operation: } & \text { sud die } \rightarrow\left(\varnothing_{\mathrm{d}-\mathrm{d})}\right. & \text { suk kura } \rightarrow\left(\varnothing_{\mathrm{k}}-\mathrm{k}\right) \\ \text { Outcome: } & / \emptyset_{\mathrm{d}} / \text { sud die } & / \emptyset_{\mathrm{k}} / \text { suc cura }\end{array}$

\footnotetext{
${ }^{1}$ In this representation, $\emptyset_{c}$ represents an unspecified consonantal position. $\mathrm{W}_{1}$ and $\mathrm{W}_{2}$ stand for word-1 and word-2.

$2 \mathrm{Tj}=$ Tjäder (1955) ; $\mathrm{R}=$ Inscriptiones Christianae Urbis Romae septimo saeculo antiquiores (1922: Vol. I; 1935: Vol. II) ; CIL = Corpus Inscriptionum Latinarum.
} 
The approach taken here is to interpret the gemination caused by the unspecified consonant as a chain of control indicated in brackets: $\left(\emptyset_{\mathrm{d}}-\mathrm{d}\right)$ and $\left(\varnothing_{\mathrm{k}}-\mathrm{k}\right)$. In this approach (Russo 2013), an X-bar format of the syllable is used: the syllable is a constituent, and the onset and coda are maximal projections of the syllable head; the syllable head selects or governs, or it adjoins another segment as maximal projection. This means that, here, the effect of the RS gemination rule is to convert one of the identical maximal projections into a 'coindexed' empty category (anaphorisation). This process of forming a control chain can be expressed as: $\left(\left(\varnothing_{\mathrm{Y}}\right)\left(\mathrm{Y}^{\circ}\right)\right)$, the chain: $\left(\varnothing_{\mathrm{i}}-\mathrm{C}_{\mathrm{i}}\right)$ 'su[dd]ie'.

In these chains of control under contiguity, the initial consonant of $\mathrm{W}_{2}$ (die or cura) acts as a possible controller of the contiguous unspecified consonant. This leads to its interpretation as a geminate.

(12) Classical form Variable Orthographies

Underlying Late Latin ĂD $<$ a $>/<$ at $>/<$ ad $>$ $/ \mathrm{a} \emptyset_{\mathrm{c}} /$

This same mechanism is behind the gemination induced by the other proclitics. Some representative examples are listed in (13), all of which are attested medieval Latin forms from Southern Italy (Russo 2011).

(13) Italian Medieval Latin $/ \mathrm{a} \emptyset_{\mathrm{c}} /, / \mathrm{e} \emptyset_{\mathrm{c}} /, / \mathrm{i} \emptyset_{\mathrm{c}} /$ (Southern Italy)

(a) ĂD (preposition): at tuis (Salerno 823, ChLA 50, IX.10), a tui heredibus (Rota 813, ChLA 50, III.16) $=/ \mathrm{a} \emptyset_{c} /$

(b) ĚT (conjunction): e tui (Rota 813, ChLA 50, III.15), tu e tuique (Nocera 857, ChLA 51, X.13) $=/$ e $\emptyset_{c} /$

(c) SED (conjunction): set tibi (Nocera 857, ChLA 51, X.10, 857) = /se $\emptyset_{c} /$

(d) IN (preposition): illocum ubi (Salerno 882, ChLA 52, XIV.5), illocum (Salerno ChLA 52, XVIII.13, 882), il locum (Salerno 855, ChLA 51, II.4) = /i $\emptyset_{c} /$

(e) Sī (conjunction, si $\times$ quid): qui sit meni[m]e (Sarno 824, ChLA 50, X.15), qui si menime (Salerno 856, ChLA 51, VIII.24), quit si mmenime (Nocera 893, ChLA 52, XXVII.19), quit si mminime Salerne 897 ChLA 52, XXXI.29) $=/ \mathrm{si}_{\mathrm{c}} /^{3}$

As is shown in (13) for Late Latin, the gemination that applies in the contexts where syntactic contiguity is established between an

3 In sit meni[m]e, the graphical $<\mathrm{t}>$ is an hypercorrected form which indicates a geminate $[\mathrm{m} \mathrm{m}]$. 
unspecified consonant in $\mathrm{W}_{1}$ and the initial of $\mathrm{W}_{2}$ gives rise to the Italian process of Syntactic Doubling, Raddoppiamento Sintattico (RS).

Lexical RS is a typical phenomenon of Italo-Tuscan and CentralSouthern Italian dialects, which derives from the asymmetrical assimilation in phono-syntax of an unspecified final Latin consonant of Word $_{1}$ to a specified C- of Word ${ }_{2}$, in a $\mathrm{W}_{1} \mathrm{~W}_{2}$ sequences. It is thus here hypothesised that AD, ET, SED, IN, SI all have an unspecified -C underlyingly. This empty position, which is present in the lexical structure is realised phonetically: thus, gemination is associated with the unspecified -C position (Russo 2013a).

(14) It. e tu e[tt]u 'and you' Lat. $\breve{E} T$ TŪ

In this formalism of the diachronic facts, the final empty position of a proclitic $\left(\varnothing_{c}\right)$ is licensed by control under contiguity. As in Kaye, Lowenstamm \& Vergnaud (1985), it is assumed here that the only form of underspecification is unspecification, a type of emptiness.

Take the case of proclitic functional heads, where these are prepositions in PPs: [PP il locum] - [P1 ... [n...]] 'in (the) place'. In this derivation, the functional head $(\mathrm{P})$ is merged with a category head + root $(\mathrm{n}+\sqrt{ })$. This introduces a proclitic that asymmetrically c-commands the root $\left[P \emptyset_{c}[n, \sqrt{C} \ldots]\right]$. All the (pro-)clitics have a syntactic fixed position and they cliticise on a contiguous host which they c-command. This syntactic condition triggers the lexical RS with the empty category, a primitive $\left(\emptyset_{c}\right)$. When this c-command relationship is established in the syntax, gemination follows automatically in the phonology.

The same process happens in Old and Modern Italian, shown in (15).

(15) Old Tuscan (all TLIO, www.ovi.cnr.it) ${ }^{4}$

Geminates are also represented graphically and the following are common forms (Russo 2013).

(a) $\breve{\mathbf{E T}}$

Old Tosc. e come and eccome (XIIIc., Laude cortonesi) (1318-20, Fr. da Barberino). Hypercorrected forms are also found: et eccome, in which the conjunction $\breve{\mathrm{T} T}$ is already cliticised.

(b) $\breve{\mathbf{E T}}$

Old Sienese evviva XIVc. (1367, Le lettere del Beato Gio)

4 The TLIO Database contains almost all medieval texts written in a variety of Old Italian up to the XIV c. 
(c) $\mathbf{D E} \mathbf{A B}$

Old Tosc. dapprima XIVc. (end XIII c., Tristano Riccardiano)

(d) $\mathbf{D E} \mathbf{A B}$

Old Flor. daccapo XIVc. (1305, Cronica di Paolino Pieri)

(e) SĪ x QUD

Old Tosc. sennò (2 half XIIIc. Frate Ubertino)

(f) SĪ x QUD

Old Flor. sennonché (1375, Chiose falso Boccaccio)

(g) ĂD

Old Flor. appena XIIIc.: appena puote (1260-61, Brunetto Latini)

These RS forms have become graphically represented in Modern Standard Italian as: evviva, dapprima, daccapo, sennò, appena. In the control by continuity account these would be represented as: $e\left(\emptyset_{\mathrm{v}}-\mathrm{v}\right) i v a$, $d a\left(\varnothing_{\mathrm{p}}-\mathrm{p}\right)$ rima, se $\left(\varnothing_{\mathrm{n}}-\mathrm{n}\right) \dot{o}, a\left(\emptyset_{\mathrm{p}}-\mathrm{p}\right) e n a$.

In addition to these cases, there are also instances of productive RS which are not graphically represented in the modern standard, although they are still variably attested in old documents.

(16) Non-orthographic RS

$$
\begin{aligned}
& \text { It. }<\text { e tu> } e\left(\emptyset_{\mathrm{t}}-\mathrm{t}\right) \mathrm{L} \quad \text { Lat. ĔT TU } \\
& \text { It. }<\text { a te }>a\left(\emptyset_{\mathrm{t}}-\mathrm{t}\right) e \quad \text { Lat. ĂD TE }
\end{aligned}
$$

The final type of gemination considered here occurred within monomorphemic forms. Additionally, these geminates occurred when the stop-stop clusters of Latin (-CT-) became geminates by diachronic regressive assimilation, as in (17a). As we see in (17b) and (17c), there is also a lexical availability of $(\varnothing)$, which is an unspecified maximal projection. This is the target of Move in the control chain of the type [fatto] Ita. fatto 'fact'. This also happens in the RS chain shown in (17c).

(17) (a) Lat. FACTU > /fa $\left(\phi_{\mathrm{t}}-\mathrm{t}\right) \mathrm{u} />$ Ita. [fát:o] 'fact'5

(b) $\left(\mathrm{f}(\mathrm{a} \emptyset)-(\right.$ to $) \quad\left(\mathrm{fa}^{\circ}\left(\emptyset_{\mathrm{t}}\right)\right)($ to $)$

(c) Ita. $e$ tu $<$ lat. $\breve{E T}$ TŪ RS [ettu] $\rightarrow\left(\mathrm{e}^{\circ}\left(\emptyset_{\mathrm{t}}\right)\right)\left((\mathrm{t}) \mathrm{u}^{\circ}\right)$

$$
\left.\ldots v^{\circ}\left(\varnothing_{C}\right)\right)\left(( C ) \left(v^{\circ} \ldots=\left[\ldots v C_{i}\right)\left(C_{i} v \ldots\right]\right.\right.
$$

\footnotetext{
5 -C- becomes unspecified in stop-stop clusters (-CT-).
} 


\section{The diachrony of geminates and control by contiguity}

\subsection{Control by contiguity in derived geminates}

As discussed in the previous section, shown in (18), and summarised below, the triggers of synchronic and diachronic gemination have as part of their structure a final empty consonant originating from a diachronic despecification.

(18) Proclitics: /e- $\emptyset_{c} /, / a-\emptyset_{c} /, / s e-\emptyset_{c} /, /$ da $-\emptyset_{c} / \ldots$

The despecified segments can be controlled and result in gemination when they are followed by a filled onset, such as in 'liaison' contexts. The gemination builds up a chain for which the format is: $\emptyset_{c}-C$. This is a relation that is termed control by contiguity and it applies between the empty, unspecified segment present in the structure of $W_{1}$ (proclitic) and the specified contiguous segment in the onset of $W_{2}$. A despecified segment $\left(\phi_{c}\right)$ can be controlled and results in gemination in contexts where it is followed by a filled onset.

The syllabification treats geminates as two positions, and ensures that they are heterosyllabic, as in (19).

$$
\breve{\mathrm{AD} T E} \rightarrow\left(\mathrm{a}\left(\varnothing_{\mathrm{t}}\right)\right)(\mathrm{t}(\mathrm{e}))=\text { [at.te] 'to you' }
$$

This uses an X-bar format of the syllable:

\section{( ( ONSET) (RIME (NUCLEUS) (CODA) )}

where ONSET, RIME and CODA are small syllables (maximal projections); the nucleus is a head. This approach accommodates recursion (structural $\sigma$ ) and strict layer hypothesis/levels segregation.

In geminates derived from RS in Late Latin and in Italian, there is an empty segment that acts as a trace which is coindexed with an onset. It is this coindexation that triggers assimilation. This representation of geminates better fits the diachronic facts, namely the despecification of final Latin consonants; geminates arise from an asymmetry between an unspecified (assimilated) and a specified position (assimilator).

As it stands, the autosegmental approach to the representation of geminates (introduced in section 1 and recapped here - in (20) and the following discussion) does not embody an essential characteristic of these derived geminates, namely the asymmetry between the two positions that is masked by assimilation. 
(20) Symmetrical geminate representations

(a) Skeleton (cf. Lowenstamm \& Kaye 1984, Levin 1985)

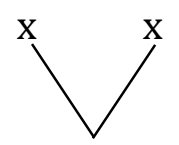

seg

(b) C and V-slots (Clements \& Keyser 1983, Lowenstamm 1996)

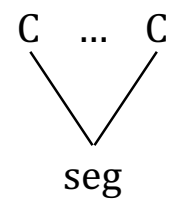

As we have seen, it is only the second half of the geminate that has the required specification to define the geminate. The first part can be considered an empty, despecified position that acts as its controller or is incorporated into a syllable as an onset before vowels as in (21).

(21) a. Liaison of ĔT 'and' / $\emptyset_{c} /$ before vowels -

Voice assimilation <ed $>$ in Latin Provinces (final -t of ET becomes voiced -d before $V$-: $\left\langle\right.$ vidit ed eos $>$, when $W_{1}$ is a proclitic)

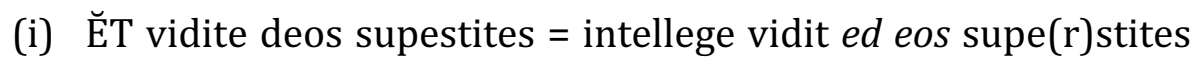
CIL XIII.2000 (Lugdunum)

(ii) $\breve{\mathrm{ET}} \varepsilon \boldsymbol{\delta} \boldsymbol{\delta} \varepsilon=$ et de $\mathrm{Tj} 20$, 88 Ravenna year $600 ; \varepsilon \boldsymbol{\delta} \boldsymbol{\alpha} \nu \kappa=$ et hanc Tj 2416 Ravenna VII c. 17; cuen ed Eutucen = quem et Eutychen Caven 120, 24 Syria II c. (-t is replaced by d before voiced stop or vowel)

b. Medieval Latin localised in Southern Italy (Russo 2013a)

(i) ӖT ed oc (Salerno 799, ChLA 20, 0702.20), ede heredes (Castello di S. Agata 845, ChLA 50, XX.32), quam ed ego (Tostazzo 859, ChLA 51, XIX.11), ed alis (San Martino al Volturno 819, ChLA 53, III.10-13)

If resyllabification applies in (21), the obstruent position can also be converted into an onset.

The asymmetric character of the phenomenon is present in the proclitic forms that we have been illustrating (shown again in 22), but it is also already attested in early Latin verbal forms following the loss of final consonants in a pre-pausal context (23). These are shown in the epigraphical data in (21-22). 
(22) Asymmetric assimilation $\mathrm{W}_{1} \mathrm{~W}_{2}$ : at porta $=$ ad porta (Pompeii CIL IV.2013 $)=[a(p-p) o r t a]$

(23) The first non-specified position (the one which is despecified in liaison) is not interpretable because of the absence of contiguity with a 'controller' leading to its loss.

Pre-pausal (and pre-consonantal) final consonant loss:

(a) superari $\emptyset$ = superarit, pre-pause, official inscription CIL V.532.1 II c.

(b) h(ic) s(itus) es $\emptyset$ (= est, end of the inscription) CIL V.920 I-II c.

(c) posuerun $\emptyset$ (end of the sentence and of the line) CIL V.1721

(d) $\operatorname{sun} \varnothing=\operatorname{sunt}$ (before pause) CIL VIII.270

(e) coeperun $\varnothing$ (end of the line) CIL.VIII 2547 II c.

(f) heres feci $\emptyset$ (end of the inscription) CIL VIII.3125

(g) feci $\varnothing$ (= fecit) CIL VIII.3678, 3687 (end of the inscription).

The data in (22) and (23) show that already at this point in history, the lexical representation of final consonants was of a lexically reduced, despecified nature. Through the despecification of Latin final consonants, Latin and Italian geminates show that we are not dealing with a 'post-cyclic' empty node convention (Ingria 1980), instead, the unspecified position is present prior to assimilation.

The trans-syllabic regressive assimilation results from the presence of consonantal specifications in the onset following a final syllable with an unspecified final position. This corresponds to the unmarked situation and explains the unmarked character of regressive assimilation. It follows from this that only one position in a geminate is specified, the rightmost. In the other position (on the left), the specifications are not inherently present: the leftward position is empty and constructed identically to the contiguous position. 


\subsection{Control by contiguity in partial geminates}

In the 'control by contiguity' model, phonology has an interpretative character and the coindexation is an interpretive process. There are three types of geminates, two of which have a clear asymmetrical property (24).

(24) Geminate types

(a) Type I: true geminates (lexical) - one feature matrix is linked to two segmental occurrences; therefore, every modification can only involve the two segments that share the same matrices (autosegmental prediction). True geminates or complete (= full) geminates are the simplest in the sense that they respect the biunivocal relation between the segments and features matrix. Ita. palla 'ball'. Geminates (1).

(b) Type II geminates: there are two distinct matrices in this type, from which we have a derivational rule: a [Y Y] group - an assimilation rule has been applied. Once the two assimilated segments have a common matrix (Geminates 2, see (24a)), they are identical to underlying geminates. Ita. fatto (Lat. FACTU) or suc cura (SUB).

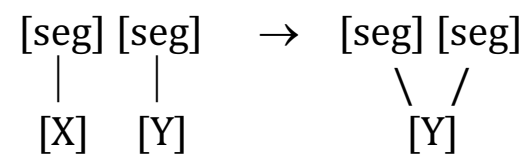

(c) Inter-assimilated (a.k.a. partial geminates) (cf. 25)<smiles>CO[15NH2]</smiles>

(i) [+nas] [ $\alpha$ nas] (specification between positions and matrix)<smiles>C1CCCCC1</smiles>

[Z]

(ii) [seg] [seg] (partial geminate)

$[\mathrm{X}][\mathrm{Y}]$

$1 /$

[Z]

Inter-assimilated geminates involve cases such as im bia 470.26 (IN VIA) or im mensem 468.26; im perpetuo 468.65 (IN) in Vulgar Latin of the Letters of Claudius Terentianus (Russo 2014, 158; Adams 1977), where the final consonant is already despecified, but an unspecified nasal 
feature is associated to the empty $\emptyset$ (a fragment of the matrix) - see also (25a). The assimilation occurs if the following consonant is an obstruent or a nasal. In partial geminates the two consecutive segments share only a few fragments of the matrix, only a few features or groups of features (see Sauzet 1988).

In the control by contiguity account, partial geminates must identify a group of autonomous features. The geometry of the geminates involves not a 'univocal' relation (equivalent to a single root node) between the elements of the matrix and the segmental chains. We must determine which features/groups can be in a multiple relation with the following segment in the sound chain. In (24), it is assumed that control remains a licensing relation even if not all features of the controlling segment are expressed in the controlled position (as is the case with partial geminates such as nasal-obstruent sequences). So, control of nasality involves the loss of the specification for place of articulation. In (24), the notion is put forward of control under contiguity in the representation of geminate: the relation between the specifications and the geminate positions is the same as the relation between a specified position and a contiguous position which it controls.

The mechanism of control by contiguity can apply also to the segments that share only one part of their features, as in homorganic nasals. These are essentially partial geminates and again show the asymmetry of the relationship. Partial geminates are derived in Latin and in Italian, often from nasal-final proclitics. As for partial geminates, assimilated geminates are of two types: those that result from assimilation within words (25b) and those previously discussed (25a), which we could also call 'accidental geminates' - that is, those where two segments meet each other at the boundary between $W_{1}$ and $W_{2}$.

(25) (a) Partial geminates in epigraphic Latin, $\mathrm{W}_{1} \mathrm{~W}_{2}$

(i) IN im balneum CIL IV.2410 = in balneum; cf. tan durum IV.1895 = tam durum (Pompeii)

(ii) IN im pace R I 16, im pacem R I 484

(iii) IN imvictissimorum CIL VIII.71 (Provinciae Tripolitana et Byzacena); imfanti CIL VIII.3349 (Lambaesis); cf. iandudum CIL X.476 IV c. (Southern Italy) $=$ iam

(b) Cases within words leading to the same effect:

[c] omvocassent Tj 10-11, B IV 2 Syracusae fin V c.; imfra Caven 117, A2 middle II c. 
In the case of partial geminates, it is necessary to assume that control remains a licensing relation, even if only some features of the controlling element are translated into the controlled position.

In Latin and Italian, partial gemination in control by contiguity requires that the despecified position controlled by a following consonant, is associated to a nasal autosegment: if the last position in a proclitic is only specified by nasality, other specification can be brought by control. As in the other geminates, control applies from right to left and because almost all the specification comes from the rightmost member, it reveals the asymmetric nature of the structure. The suggestion here is that geminates are more adequately described through a mechanism which operates within a level called control by contiguity. Control is interpreted phonetically as a copy. ${ }^{6}$

\subsection{One or two segments?}

In terms of their distributional properties, geminates appear to be two segments, but unlike consonant clusters, they resist intrusion by epenthesis; furthermore, they are resistant to processes that would affect only one of their parts if each part were a separate segment. This notion is introduced in section 1 as geminate inalterability (following Hayes 1986). Segmental theory allows us to transcend this paradox, associating positions and the segment in a non-biunivocal way: a single matrix of features is associated to the two positions. The univocal matrix of features explains the other properties - as in (26), there is only one set of specifications linked to two positions.

$$
\begin{aligned}
& \mathrm{x} x \\
& \backslash / \\
& {[\mathrm{F}]}
\end{aligned} \quad=\quad \text { Feature Matrix }
$$

Two type of interpretation can be drawn from this representation. The weak interpretation has to admit that the geminates are made up of only one set of specifications and of two positions. The strong interpretation is that geminates are a matter of an autosegmental theory. Are these a graphic trick, or a mere notational variant?

\footnotetext{
${ }^{6}$ This assumes that UG proposes a set of possible phonological systems characterised by the presence or absence of a particular geminate which a language learner can choose. We must determine which of the typological systems are the marked ones. The logic of language acquisition implies that phonological systems without geminates are non-marked and that a child does not select the hypothesis of a phonological form between such objects until they meet them.
} 
The question we want to ask is whether the peculiarities of geminates follow from the principles established by autosegmental theory or whether there are a few properties of geminates that fall outside of this. Autosegmental theory can only predict the inseparability of these two positions linked to an identical matrix (the integrity of geminates should be guaranteed by the no-crossing constraint/convention, but see section 4.2). Under an autosegmental approach both positions are identically linked to one single set of specifications. This means that geminates are handled as a whole. In our approach (as set out in section 2 and in parts of this section, and as is also to be separately considered in section 4), the two positions are the segment projection, i.e. positions are projected from specifications: only one position in a geminate is specified - in the other position, features are not inherently present. The other position is empty and built as identical to a contiguous position.

\subsection{The asymmetry of geminates and empty categories}

The autosegmental approach does not appear to model the central characteristic of geminates that we discuss - namely, the asymmetry of the two positions composing the geminate vs. the symmetry of geminates under an autosegmental approach (where each position in a geminate has an identical relation to specifications). This asymmetry is evident when geminates result from assimilation: there is only one position lexically associated to a matrix, the other one is obtained derivationally.

In the framework sketched out above, the mechanism that is argued to most adequately describe the properties of geminates is a relation called 'control' that is applied to a non-specified (empty) position - by a contiguous specified position (Kaye and Lowenstamm suggested an approach of this type in Dell, Hirst \& Vergnaud 1984, Sauzet developed it in 1988 for Berber Geminates; see also Russo 2013 for Italian and Late Latin geminates). The empty position in geminates is contiguous to the next slot, which is a consonant in onset position. Control under contiguity yields geminates. Control is relevant to contiguity only if it is not contiguity within a constituent. We therefore have an empty position both in long vowels and in consonant geminates. In long vowels (VV) the empty position is contiguous to the head of the rhyme and belongs to the same constituent (however, contiguity is relevant, even if not combined with government). The term control for consonant geminates avoids confusion with government (in vowel geminates), which in here implies constituency. 
This control relation is translated phonetically by the attribution of features from the specified position to an unspecified position; the configuration yields geminates as set out in (27).

(27) Geminate notation ${ }^{7}$

a. (i) $\varnothing-\mathrm{F}$

(ii) $\mathrm{F}-\varnothing$

In Latin and Italian consonantal geminates have the controller on the right (i), but control under contiguity can also apply when the controller is on the left (ii), as suggested for Berber Geminates by Dell \& Elmedlaoui (1985) — see (29).

This notation can be extended to partial geminates via a feature matrix decomposition (see Sauzet 1988):

b. $F_{i} \quad F_{j}$

$\emptyset \quad-F_{k}$

$\left(\mathrm{F}_{\mathrm{i}}, \quad \mathrm{F}_{\mathrm{j}} \ldots\right.$ are the sub-matrix $)$

(27b) accounts for the treatment of final nasals in Latin and Italian, where nasality cannot be supplemented with consonantal specifications, but receives specification via contiguity (e.g. im bia 470.26 IN VIA).

This notation does not contradict the weak interpretation of the autosegmental representation: one set of specifications in two positions. Here as well, one set of specifications is linked to two positions. For geminates it is crucial to establish which $\mathrm{C}$ is the controller segment and which $C$ is the controlled (empty) segment: $\emptyset$-F or $F-\varnothing$. This configuration excludes geminate splitting and correctly predicts inalterability and integrity (explaining why once formed, geminates only simplify and never break). Meanwhile, in the autosegmental approach up to now, the inalterability of geminates has to be explained with extra mechanisms.

Conversely, in the $\emptyset_{c}-C$ format, the inalterability is a consequence of the asymmetry of geminates: one position is directly related to specifications (according to our assumption, projected from them), while the other is related indirectly through contiguity to the specified position. In this perspective, positions and specifications are not independent objects. This assumes that positions are a projection of specifications (that is, those specifications are expressed phonetically). Control is a situation where specifications are expressed in a position. It follows that one could have this asymmetric representation also for

7 (i) and (ii) are to be read as [FF] - the empty position (controlled by a contiguous position) is phonetically interpreted as having the same features. 
lexical synchronic geminates, as in Italian (palla 'ball'). Furthermore, the mechanism of control by contiguity explains more directly the complementary between the assimilation process and the loss of final Latin consonants. We can propose a principle: an empty position which is not controlled within a level is not realised nor interpretable. If we suppose that a final vowel in proclitics like Latin ET lexically projects a branching rime, we need syntactical contiguity to be established to allow the empty position $\emptyset_{\mathrm{t}}$ be controlled and realised.

The complementarity between the assimilation and the loss of the final consonant is natural in that analysis: the two processes are generated by an empty position which sometimes can be interpreted (in assimilation) and sometimes not.

\subsection{The inadequacy of the symmetric approach}

The fact that geminates result from assimilation suggests an asymmetry between the position that assimilates and an assimilated position (at least diachronically). In the representation used here, the assimilation is reduced diachronically to a 'despecification' in a context where the control by a contiguous segment is possible. In an autosegmental representation, the initial asymmetry is non-recoverable once the assimilation is effected.

We recall that Dell \& Elmedlaoui (1985) use the representation given in (28) for geminates in Imdlawn Tashlhiyt Berber (ITB).

(28) Synchronic representation of geminates

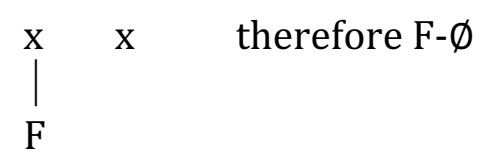

Their empirical motivation is that only the first part of the geminate has the necessary specifications to determine the sonority degree which allows a segment in ITB be a centre of a syllable, while the second part of the geminate is an empty position (Dell \& Elmedlaoui 1985, 27).

In (29) only the first position is associated to a feature matrix, therefore this representation ( $\mathrm{F}-\varnothing)$ applies, as only the first part in ITB possesses the specifications required (see Sauzet 1988). F is only associated to the second position later on.

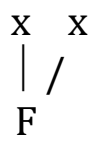


Dell \& Elmedlaoui (1985) develop their analysis in autosegmental terms. However, they point out that in their representation (29) there is a basic asymmetry inherent to lexical geminates. In ITB the right part of the geminate is subordinated to the left part. This asymmetry can be resolved in an autosegmental framework reducing the opposition between a specified vs. a non-specified position. We argue that the OCP interdiction applies to (articulatory) melodies and not to positions: it is the contiguity between melodies which is relevant. The application of the OCP at the melodic level requires that geminates are not the effect of the association between a matrix and two positions. Thus, for geminates the unspecified slots must be interpreted as segmental ECs.

In an autosegmental framework, empty positions are not ECs, instead we think that geminates are a complex object in which the unspecified slots must be interpreted as segmental ECs. Therefore, we have to distinguish here between non-segmental and segmental ECs: (a) the former occurs anywhere in phonological representations and does not need a lexical specification; (b) the latter is lexically introduced and can remain empty at surface level or may be phonetically identified. These two varieties of ECs are universal categories. They are parametrised. Within the autosegmental approach the two positions of geminates are treated as a whole, however the Latin and Italian facts strongly invoke the analysis of geminates as sequences of two segments, one empty and the other specified.

Therefore, the position developed here proposes that Latin and Italian geminates consist of the control by contiguity of an empty position on the same level, as in (30).

(30) Control by contiguity: sud die $\emptyset_{\mathrm{d}}$-d (the subscript $d$ indicates the coindexation with the $d$ onset of the $\mathrm{W}_{2}$ die) or It. 'fatto' Lat. FACTU

(a) A 'C' class of segments controls a contiguous empty position to its left.

(b) Class C: all segments except /sC/.

The OCP applies to the $\emptyset_{\mathrm{d}}$ - $\mathrm{d}$ type. It states that on one level two contiguous units are distinct. They are not dependent on the relation between this level and other levels. The application of the OCP at the melodic level requires that geminates are not the effect of the association between a feature matrix and two positions. As has been noted, the consequence of the principles proposed above (positions are projected from specifications) allows a new formulation of the OCP, which is usually used as a filter on representations. Given the classical 
formulation of the OCP, we can assume that on melodic level elements cannot be distinguished unless they are different. The suggestion here involves a different formulation of the OCP where specifications can project positions, but reduction results from the necessity for positions to be independently interpreted.

\subsection{Gemination by control}

In Italian geminate vowels also control a contiguous empty position to the right: $\mathrm{v}-\emptyset$. In Italian there is a lexical contrast between the following forms:

(a) fa $\varnothing$ to [faato] fato 'destiny'

(b) f a $\emptyset$ - to [fatto] fatto 'fact'

Both configurations have an unspecified position $(\varnothing)$. In (a) only percolation applies in a constituent. In (b) control under contiguity is possible. The consonant instead controls a contiguous position to its left, in Italian and in Latin. The gemination in both cases is just a phonetic effect of the interpretation of an empty position.

We claim here that geminates are complex objects and not segments carrying a feature [+long]. Empty positions in an autosegmental framework are not ECs: the nature of ECs does not change whether or not the slots are linked with phonetic specifications. If, however, relations between slots and matrices do not fall within the general framework of autosegmental relationships, unspecified slots have to be interpreted as segmental ECs. In this approach, ECs are completely unspecified and only identified by the contiguous segment; this assumes that such ECs $(\varnothing)$ exist on the segmental tier and that such ECs are present at a lexical level.

For geminates, the relation between timing units and matrices does not fall into the general format of autosegmental relationships and the unspecified slots must be interpreted as segmental ECs (Sauzet 1988). Therefore, we distinguish here between non-segmental and segmental ECs: the first type occurs anywhere in phonological representations and does not need (but can have) a lexical specification; the other type is lexically introduced and can remain empty at surface level or may be phonetically identified.

These two varieties of ECs are assumed to be parametrised universal categories. This requires (i) a parameter specifying the way in which syllabic structures are constructed on non-segmental ECs, and (ii) a parameter converting a non-segmental EC into a segmental one. This parameter can be called the compactness parameter (see Sauzet 1994): a 
language is compact if the non-segmental ECs it contains cannot be converted into segmental ones. It is not compact in the opposite case.

\subsection{Should we give up the skeleton?}

For an autosegmental framework there are problems involving the identification of two contiguous positions in a geminate and their relation to the specifications' positions. Thus, the status of unspecifiedness has to be reformulated. It is not in our approach an effect of the lexicon, but it implies a structural mechanism of identification. The approach developed up till now in this article requires a theory that includes amongst its procedures control by contiguity. This approach underlines the asymmetry between the two positions of geminates, and goes further in assuming that if positions are projected from specifications this means that there are no independent $\mathrm{CV}$ positions. This also makes the strong interpretation that geminates are a matter of an autosegmental theory by extension.

Within an autosegmental approach, the two positions of geminates are associated to only one set of specifications, meaning that geminates are treated as a whole. However, the facts strongly invoke the analysis of geminates as sequences of two elements, one empty and the other specified. If positions are projected from specifications this means that there are no independent CV positions. Thereby this creates a problem for the autosegmental framework because it does not allow for the presence of independent unspecified segments and positions. The asymmetry between an empty segment and a specified segment explains the different rules that involve the first or the second element. A sequence of $\emptyset$-C is different from a sequence of C-C.

Autosegmental phonology is not primarily concerned with constituent structure. When linking implies spreading, this linking should merge with prosodic structure assignment. If the identity and the cohesion of the two elements of the geminate is not explicable in autosegmental theory, we could consider the hypothesis that they are constituents. If we consider the geminates as constituents, then the asymmetry which we have referred to between a strong position which controls the weak position would be natural. The reason is that the notion of constituency is inseparable from the one of 'head': a constituent implies a notion of dominance. But if geminates are heterosyllabic, they cannot be considered a constituent, since this fact would violate a tree structure. Vowel geminates $\mathrm{v}-\emptyset$ can instead be considered a kind of a harmonic constituent in the sense of Zubizarreta (1984). The contiguity relation is therefore different from constituency, which is a harmonic relation; but it can be related to it. 
We could say that contiguity is a primary relation which contributes to the definition of a constituent, but it exists also between two successive segments that do not form a constituent. The contiguity can be harmonic, even if it does not participate in a definition of a constituent, that is: control by contiguity is also a harmonic contiguity. This allows for a unified approach to geminates.

If the contiguity relation between these two elements and the dominance relation is taken into account, the conclusion is that geminates are not constituents - rather, they are reminiscent of transconstituent government in Standard GP (i.e. Harris 1990; see Sauzet 1988). To have constituency, contiguity must be composed of a relation between a segment which is a head and one which is not, and it must be associated with head and projections; therefore, contiguity could give rise to unbounded constituents. That each constituent belongs to one higher constituent in any grammatical component follows from the projection format, as in X' representations. Geminates are bounded as a consequence of having been defined on only one level - they do not project as a constituent.

This means that positions and specifications are not always in a bijective relationship. Empty positions can only be sisters to a specified head or its projections (Kaye \& Lowenstamm 1984), as in (31).

$$
\begin{aligned}
& \text { a. } \sigma \quad \text { b. } \sigma \\
& \bigwedge
\end{aligned}
$$

The empty position in such structures is contiguous to the head and belongs to the same constituent. This could be the interpretation of long vowels which are a case of local harmony: specifications of the vowel are copied and percolate into unspecified positions, as in (32) (see Sauzet 1988).

$$
\begin{aligned}
& \sigma \\
& \mathrm{x} \emptyset-\mathrm{C} \quad \text { [vCC] Ita. [fatto] } \varnothing \text {-t o }
\end{aligned}
$$

Or in Latin (e.g. 2) and Italian RS [ettu] Italian $e$ tu 'and you' $\emptyset$-t u.

Control under contiguity applies to consonantal geminates - this means that bare concatenations have some relevance, i.e. the segment can contribute to the interpretation of a neighbouring segment, a contiguous unspecified position, interpreted as identical to the specified one. Contiguity is relevant to control only because it is not contiguity 
within a constituent, but on this view, it is part of the relation of constituency.

\section{$3.8 \varnothing-$ absolute nothingness}

Kaye \& Lowenstamm (1984) suggest a recourse to empty elements that do not put up an equivalence of $x y$ and $x \emptyset y$, "where $\emptyset$ is clearly nothing like a segment".

Latin and Italian have underlying empty positions on the segmental level prior to the construction of metrical structure on the surface: $\emptyset$-s (where $s=$ segment). This puts a relation just with the segment matrix, which is maximally underspecified, but entirely identified by the contiguous segment. Unspecified slots are interpreted as segmental ECs.

On this view, the status of unspecifiedness has to be reformulated in a framework where the attribution of phonetic interpretation to an empty segment is not always an effect of the lexicon, but implies a structural mechanism of identification. As we have seen some rules operate on representations, as in (33a), or on some unspecified matrix, as in (33b).

a. $\varnothing$

b. $\varnothing$

$\mathrm{N}$

This requires a reassessment of a theory for the interpretation of underspecified positions in phonology that includes amongst its procedures control by contiguity. We have to admit that the harmonic contiguity applies by default to the empty position, if this position cannot be otherwise interpreted.

\subsection{From Latin to Italian}

An autosegmental framework makes it necessary to stipulate that, in Italian, the first part of a geminate can be linked to any melodic specification, where those specifications are also linked to another position. The logic of autosegmental representation is that if a position is linked to some specification, it is of no significance what other positions do not share them. In the case of gemination, and particularly from a diachronic perspective, a better approach is to represent geminates with an empty position and to use the contiguity relation to interpret it phonetically. 
In Late Latin we have seen from the data above that an unspecified position can be underlyingly present or it can result from lexical despecification. The empty position created must be controlled by the following consonant. This defines regressive consonant assimilation (the unmarked case of assimilation may be the only one).

Both underlying empty positions (as in Italian) and despecified positions (as in Latin) are subject to leftward control: $\emptyset_{c}$ is the first part of geminates. ${ }^{8}$ On this view, geminates take advantage of the notion that contiguity is a primitive of linguistic theory. Contiguity is a crucial concept in the definition of constituency also for elements like geminates, which do not belong to the same constituent of a higher rank. Heads can govern contiguous elements (as in geminate vowels), yielding constituents. Thus, constituency implies the notion of head (government and projection) and contiguity. We suggested above that contiguity is relevant also if it not combined with government. 'Control' does not imply constituency. But still, putting forward the notion of control is to build a metrical structure without considering consonantal geminates as constituents. The effect of control can be fully identified only in relation to a theory of specifications and metrical structures. The distribution of unspecified positions can be accounted for if the government relations have been established. Control operates in this distribution, but it does not define unspecified positions. Liaison and RS are the consequence of the meeting between the progressive deployment of syntactic ordering and the regressive movement in the building up of internal phonological linearisation through syllabification. In this approach to phonological theory (syntactical phonology), linearity derives from constituent structure through the specification of head location or the directionality of government and anaphoric chains. In phonology, structure is built over a lexically given linear string (a concatenation).

To sum up, in syntax, linearity is derived through directionality. In phonology, directionality is only recognised (but it is there from the beginning). The 'control by contiguity' approach proposes to reject this asymmetry, generalising the derivation of linearity through the grammar.

Within this approach, we could also say that the effect of the gemination rule in Latin and Italian and syntactic doubling (RS) is to convert one of the identical maximal projections into a coindexed empty category (anaphorisation); the final empty position of $W_{1}$ is coindexed with the initial onset of $\mathrm{W}_{2}$, as in (34).

$\left(\left(\varnothing_{\mathrm{Y}}\right)\left(\mathrm{Y}^{\circ}\right)\right)$

\footnotetext{
8 The directionality is not a consequence of contiguity, but rather is given by prosodic and metrical structure.
} 
Given the chain $\left(\varnothing_{\mathrm{i}}-\mathrm{C}_{\mathrm{i}}\right)$, this coindexation in the case of liaison derives from movement, which is the only possible equivalence of an autosegmental propagation process that supposes superposed levels of concatenation.

For liaison before a vocalic nucleus, this approach proposes the movement of the vocalic head (iteration of movement which produces onset-nuclei structures in the lexicon). The presence in the trace position of a specific head, such as that of a vowel in the case of liaison, suspends the extrasyllabicity of the final unspecified segment. In the case of vocalic liaison, movement determines the legitimate position for the segment, thus creating a non-empty nucleus. Within this coindexation of a segment by a following onset, the coindexed object is a null object, or it has a specification which determines a partial assimilation (typically of nasals), or it has a specification that is not expressed locally (as in voicing assimilation in liaison). Liaison is the explicative principle behind the diachronic process of decomposition. This assumes the lexical availability of $(\varnothing)$, a maximal projection, non-specified (precisely: a despecified segment), as a maximal projection, a target of government but also of movement. This unspecified position is a primitive object of the theory. The difference between the two processes (gemination and liaison [ed ego] $\left(\mathrm{e}^{\circ}\right)\left(\varnothing_{\mathrm{d}}\right)$ ET EGO) is in the acquisition of a coindexated onset-nucleus: in one case the movement introduces the vowel to a coindexed empty position (liaison); in the case of gemination the coindexation determines the geminate interpretation of a trace linked to the coda (gemination). With RS we are faced with the licensing of an empty syllable nucleus due to its word-final position (cf. Word Final Parameter) under a format of trace segment chain (seen also in previous sections).

$$
\begin{aligned}
& {[\mathrm{ettu}] \rightarrow\left(\mathrm{e}^{\circ}\left(\emptyset_{\mathrm{t}}\right)\right)\left((\mathrm{t}) \mathrm{u}^{\circ}\right) \text { Italian } e t u} \\
& \left.\ldots \mathrm{v}^{\circ}\left(\varnothing_{\mathrm{C}}\right)\right)\left((\mathrm{C}) \mathrm{v}^{\circ} \ldots=\left[\ldots \mathrm{v} \mathrm{C}_{\mathrm{i}}\right)\left(\mathrm{C}_{\mathrm{i}} \mathrm{v} \ldots\right]\right.
\end{aligned}
$$

(35) uses an X-bar format of the syllable: the constituents of the syllables are reduced syllables and $\mathrm{x}$ is $\mathrm{x}^{\circ}=\mathrm{V}$ (non-governable locally); otherwise $\mathrm{x}$ is $(\mathrm{x})=\mathrm{x}^{\max }=\mathrm{C}$. Onset, Rhyme and Coda are small syllables (maximal projections); only the nucleus (and the non-initial elements of a branching Onset) is a head $\left(\mathrm{v}^{\circ}\right)$. The Latin and the Italian RS gemination rule (35) converts one of the identical maximal projections into a coindexed empty category (anaphorisation). 


\section{Asymmetry in synchrony and typology}

We have seen above that, although geminates generally receive a symmetrical analysis in synchronic phonological representations, their diachronic origin is strongly asymmetric. We have also seen how this asymmetry is accounted for in the framework of 'control by contiguity'. In the upcoming final section, we will return to the issue of deriving geminate inalterability, this time with a purely synchronic, asymmetric representation using the Strict CV framework.

\subsection{Asymmetric geminates}

As discussed in the introduction (and in parts of section 3), we saw that geminates are qualitatively different from both C.C and VVs in that they are universally resistant to breaking by epenthesis. We also saw that geminate inalterability cannot follow from the restriction on line crossing as classically assumed (Hayes 1986). In previous sections, an asymmetric account of geminate inalterability was developed, which at the same time reflected the common diachronic origins of geminates. In this section, we will move on to consider one possible explanation for the integrity of geminate consonants in the Strict CV framework (Lowenstamm 1996, Scheer 2004). Strict CV is an autosegmental framework where representations are formed of two main tiers - the melodic tier of features/segments and the skeletal tier made up of strictly alternating $\mathrm{C}$ and $\mathrm{V}$ slots.

The account developed here tentatively proposes that the melodic portion of geminates is distributed asymmetrically in the syllable structure, at least in the UR. Radically, it is proposed that the geminate is not associated to two C positions in the UR. Instead, it is only the two skeletal/C positions that define the geminate's structural description. This representation is shown in (36).

(36) UR Asymmetrical geminate /tapro/ Italian tappo 'lid'

$\begin{array}{cccccc}\mathrm{C}_{1} & \mathrm{~V}_{1} & \mathrm{C}_{2} & \mathrm{~V}_{2} & \mathrm{C}_{3} & \mathrm{~V}_{3} \\ \mathrm{l} & \mathrm{l} & & & \mathrm{l} & \mathrm{I} \\ \mathrm{t} & \mathrm{a} & & & \mathrm{p} & \mathrm{o}\end{array}$

In this structure, all of the melody of the geminate $/ p /$ belongs to $C_{3}$. However, $\mathrm{C}_{3}$ is not like an ordinary singleton or even a coda-' $p$ ' because it is preceded by a wholly empty $\mathrm{CV}$ unit $\left(\mathrm{CV}_{2}\right)$.

The empty $\mathrm{CV}_{2}$ is an essential part of the underlying form of the geminate. However, unlike standard assumptions, the melody of $\mathrm{C}_{3}$ does not spread to $\mathrm{C}_{2}$ in the UR. 
The emptiness of the structure may look 'frightening', but the way that the empty structure is licensed will be explained. First, we will show that this structure correctly predicts the inalterability of the structure, and that it completely rules out the possibility of breaking a geminate by epenthesis, unlike long vowels and consonant clusters.

The asymmetrical structure proposed in (36) breaks another symmetry: the symmetry of heavy syllables. While all heavy syllables necessarily involve two CV units (Ulfsbjorninn 2014, Faust \& Ulfsbjorninn to appear), geminates are no longer seen as structurally analogous to long vowels, because a long vowel involves melody that branches between two $\mathrm{V}$ positions. Likewise, heavy clusters or the RT type are not structurally analogous to geminates, because RT clusters have melody that is distributed across two $\mathrm{C}$ positions.

This representational difference makes long vowels and consonant clusters breakable, but not geminates; line crossing is not an issue but phonological separatability is. The core observation is that you cannot split monopositional melody by positional epenthesis. Or put differently: you cannot interpolate something which is located all in one position.

Given these representations, epenthesis can break up long vowels and consonant clusters (of any type, including the robust N.T's) because their melody is phonologically present in more than one position (37ab). Conversely, geminates (as shown in 36) cannot break by epenthesis because all of their melody is asymmetrically distributed in $\mathrm{C}_{3}$. There is simply nothing there to break.

(37) Breakability of LVs, NT and G

(a) LV broken by $\mathrm{C}$ epenthesis

(b) NT broken by C epenthesis
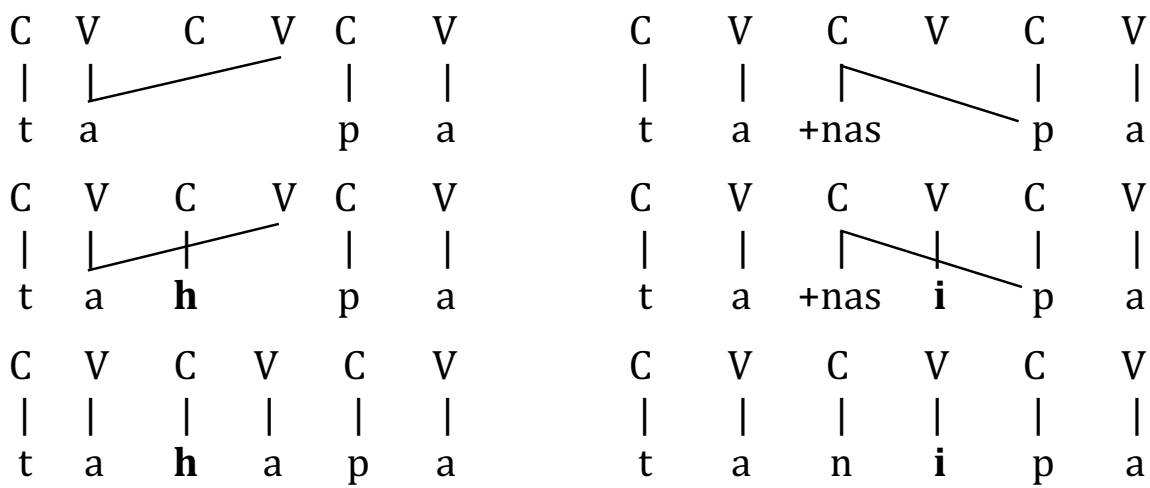

As consequence of this asymmetric representation, geminates can only be undone by simplification, as in Portuguese $\mathrm{tt}>\mathrm{t}$ gutta $>$ gota 'drop' (Szigetvari 2008) (see 38), or by epenthetic insertion to their side (usually to their left). A case of this is shown in the pre-aspiration of 
Icelandic, which replaced some historical geminates: hattur $>$ [ha ${ }^{\mathrm{h}_{\mathrm{tyr}}}$ ] 'hat' (Árnason 2011) (shown in 38).

(38) Geminate UR and unbreakable (inserted material will be an edge)

(i) UR of geminate $(t t)$

$\begin{array}{cccccc}\mathrm{C} & \mathrm{V} & \mathrm{C} & \mathrm{V} & \mathrm{C} & \mathrm{V} \\ \mathrm{l} & \mathrm{I} & & & \mathrm{I} & \mathrm{I} \\ \mathrm{t} & \mathrm{a} & & & \mathrm{t} & \mathrm{a}\end{array}$

(ii) Simplification $(t t>t)$

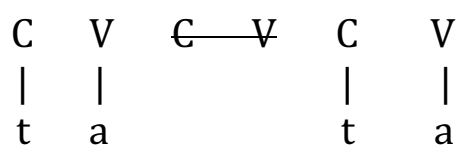

(iii) Compensatory lengthening $(t t>a: t)$

$\begin{array}{cccccc}\mathrm{C} & \mathrm{V} & \mathrm{C} & \mathrm{V} & \mathrm{C} & \mathrm{V} \\ \mathrm{I} & \mathrm{I} & & & \mathrm{I} & \mathrm{I} \\ \mathrm{t} & \mathrm{a} & & & \mathrm{t} & \mathrm{a}\end{array}$

(iv) Vowel Epenthesis to the left $(t t>i t)$

$\begin{array}{cccccc}\mathrm{C} & \mathrm{V} & \mathrm{C} & \mathrm{V} & \mathrm{C} & \mathrm{V} \\ \mathrm{l} & \mathrm{l} & & & \mathrm{I} & \mathrm{I} \\ \mathrm{t} & \mathrm{a} & & <\mathrm{i}> & \mathrm{t} & \mathrm{a}\end{array}$

(v) Consonant Epenthesis $(t t>h t)$

$\begin{array}{cccccc}\mathrm{C} & \mathrm{V} & \mathrm{C} & \mathrm{V} & \mathrm{C} & \mathrm{V} \\ \mathrm{I} & \mathrm{I} & \mathrm{I} & & \mathrm{I} & \mathrm{I} \\ \mathrm{t} & \mathrm{a} & \mathrm{h} & & \mathrm{t} & \mathrm{a}\end{array}$

\subsection{Empty structure in geminates}

The asymmetric representation of geminates decouples them from the classical symmetric representation of long vowels. Interestingly (from a Strict CV theory-internal perspective) this difference is not arbitrary. The difference between long vowels and geminates appears to follow independently from Strict CV assumptions. As we have seen, both geminates and long vowels are composed of two CV slots, one of which is a dependent $\mathrm{CV}$, as in (39).

(39) (a) Long vowel
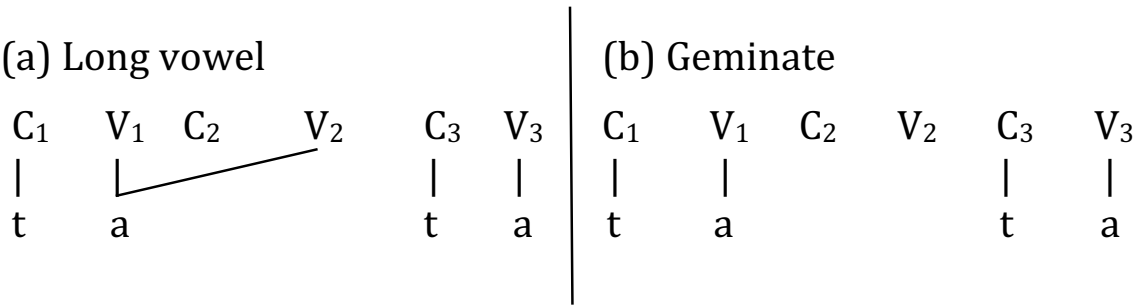
Before the licensing implications for each configuration are presented, it is important to motivate the 'Dependent CV'. This helps explain exactly which parts of the structure are required to be empty.

It is seldom observed, but certainly a fact, that in all languages with long vowels (VVs), onsets are permitted. Therefore, the maximal structure of a long vowel is as shown in (39a) $-C_{1}$ is fully filled and $\mathrm{CV}_{2}$ must have an empty $\mathrm{C}_{2}$. Similarly, in all languages that have geminates, geminates can precede vowels, so the maximal structure of a geminate is $(39 b)-C V_{3}$ is fully filled and $C V_{2}$ must have an empty $V_{2}$.

In both the structures of (39), there is a CV which is fully-filled and another $\mathrm{CV}\left(\mathrm{CV}_{2}\right)$, which is extremely limited in what it can contain. In both structures, the fully-filled $\mathrm{CV}$ is a head $\left(\mathrm{CV}_{1}\right.$ for long vowels and $\mathrm{CV}_{3}$ for geminates), while $\mathrm{CV}_{2}$ is a dependent. ${ }^{9}$ The two syllable structure configurations have different necessarily-empty bits of structure: $\mathrm{C}_{2}$ for long vowels, and $C_{2}$ and $V_{2}$ for geminates. The parts that are necessarilyempty have implications for the licensing forces that are involved in silencing the empty parts of those structures. The key difference between long vowels and geminate consonants, therefore, lies in both (a) the melody that fills the (dependent) necessarily-empty CV, and (b) the licensing that handles the necessarily-empty CV.

The next section shows that the difference between symmetric long vowels and asymmetric geminates is not arbitrary, rather it is a consequence of the condition that melody can only spread to positions that are licensed.

\subsection{Phonological forces and necessarily-empty structure}

The clearly demarcated difference between long vowels and geminates is complemented by the two licensing forces of Strict CV, government (an inhibitory force) and licensing (an enhancing force) (Ségéral \& Scheer 2001). The enhancing force, licensing, is already assumed in Strict CV to allow the spreading of material to the landing site of long vowels (Scheer 2004) (cf. earlier approaches in Yoshida 1993 and Kaye 1995).

It is proposed here that geminates originate from the opposing force, government. This opposition between licensing forces creates the doublet shown in (39). The weak $\mathrm{CV}\left(\mathrm{CV}_{2}\right)$ of long vowels is enhanced by licensing. Meanwhile the weak $\mathrm{CV}$ of geminates is silenced by government. ${ }^{10}$

\footnotetext{
${ }^{9}$ Indeed, in the templatic approach to syllable structure, positions like $\mathrm{CV}_{2}$ have been called 'recessive' (Goh 1997, Xu 2001).

${ }^{10}$ This is actually the expected state of affairs considering that this is also implicated in bogus clusters and RT clusters (Scheer 2004).
} 
(40) Licensing and governing the weak $\mathrm{CV}^{11}$

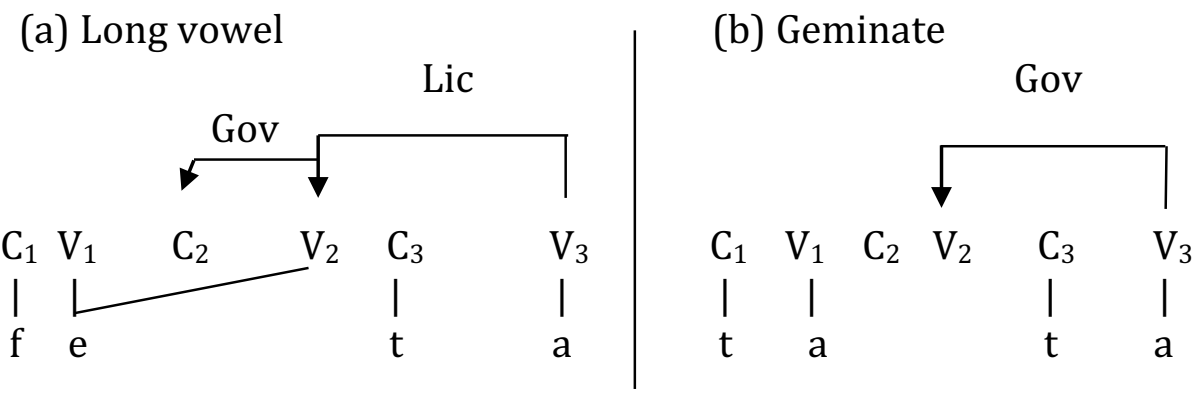

In (40a), we see that in long vowel structures $V_{3}$ licenses $V_{2}$. As a consequence of being enhanced by licensing, $V_{2}$ is permitted to host melody that it shares with $V_{1}$. $V_{2}$, being a non-governed nucleus, is able to govern $\mathrm{C}_{2}$. As a result, $\mathrm{C}_{2}$ may remain empty and phonetically uninterpreted.

Conversely, in the case of the geminate $(40 \mathrm{~b}), V_{3}$ governs $V_{2}$. Government is an inhibitory force, therefore $\mathrm{V}_{2}$ may not be filled with melody or phonetically interpreted. We assume that Charette (2003), Ulfsbjorninn (2014), Faust (2015) and Faust et al. (under review) are all correct in assuming that pointed onsets (at least some C-slots) require government to remain empty and uninterpreted. Therefore, $\mathrm{V}_{2}$ cannot govern the following empty position $\mathrm{C}_{2}$. But $\mathrm{C}_{2}$ needs government and cannot receive it from $\mathrm{V}_{2}$, which is itself governed. Therefore, $\mathrm{C}_{2}$ has no possible source of government and, because empty ungoverned categories are obliged to be expressed phonetically, it will have to be interpreted phonetically. However, we propose that $\mathrm{C}_{2}$ does not receive melodic spreading from $\mathrm{C}_{3}$. Instead, it is the ungoverned status of $\mathrm{C}_{2}$ that makes this position directly phonetically interpreted as a geminate.

This asymmetric representation is a particularly encouraging result from a Strict CV perspective, because it is satisfying to propose that melodic spreading always requires licensing. Though this conclusion would need to be fully explored in subsequent research, there do seem to be some indications that this is on the right track (at least within GP argumentation). For instance, the most widely accepted GP model of vowel harmony (Charette \& Göksel 1998) shows the spreading of melody (harmonic elements) being conditioned by licensing.

In (41), we see the proposed representation of geminates fully dressed by the licensing and government forces of Strict CV.

${ }^{11}$ In addition to correctly accounting for the empty structure. 
(41)

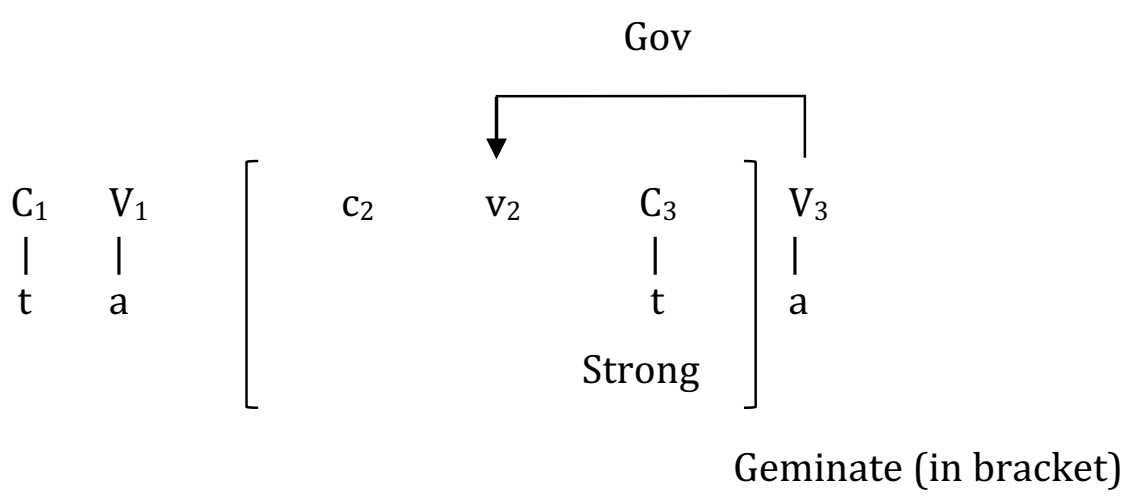

The structure in (41) also correctly predicts that vowel length should not occur before geminates. This is consistent with the observation that in many languages a long vowel may not precede a geminate consonant (occasional exceptions to this are attested). This observation receives a ready account from the structure in (41) because, in this model, geminates and long vowels compete for the $\mathrm{V}_{2}$ position of the Weak $\mathrm{CV} . \mathrm{V}_{2}$ is either governed from $V_{3}$, resulting in a geminate, or licensed by $V_{3}$, in which case vocalic melody can spread into it from the left $\left(V_{1}\right)$ (Scheer 2004).

$\mathrm{C}_{3}$ being ungoverned is a strong position (analogous to the post-coda position) (cf. Scheer 2004). Furthermore, since there is no melody in $\mathrm{C}_{2}$, the geminate is entirely composed of the strong melody (doubled by the phonetic interpretation). Unlike standard GP assumptions (Harris 1990, Lowenstamm 1996), since we do not assume that $C_{2}$ is filled with the $C$ melody in forming a geminate, it is impossible to split the geminate by epenthesis because phonologically there is nothing to split.

\section{Conclusion}

We think that the generalisations of autosegmental theories for the representation of geminates must be improved in order to recognise their diachronic and synchronic asymmetry. What we underline on the bases of distributional properties is that - unlike consonant clusters geminates resist breaking by epenthesis (geminate integrity). Geminates' stability and integrity show that there is a resistance to the processes that could affect one part of the geminate, as if it were composed of two parts (cf. inalterability, following Hayes 1986), as well as a resistance to phonological processes that split up the geminate as if it was composed of two parts. In previous approaches, the inalterability of geminates was expressed by extra mechanisms. ${ }^{12}$ In this article, we have set out two, related approaches to improve on previous analyses of these issues.

12 Furthermore, in an autosegmental representation, the initial asymmetry is nonrecoverable once the assimilation is affected. 
In the control by contiguity approach (in sections 2 and 3), where phonology has an interpretative character and builds up linearity, the asymmetry and inalterability of geminates is a consequence of the $\emptyset$-C format. This assumes that the asymmetry of the derivation of geminates is relevant to their synchronic representation, following Dell \& Elmedlaoui's (1985) lead. Stated in $\mathrm{x}$-bar theory, where syllabic structure is represented as follows: (x (y z)), predictability is induced from positional neutralisation and a licensing statement: $\alpha \mathrm{F}$ must be licensed in the x-bar structure. Or, given the nature of the concatenation, these despecified Latin geminates can be analysed in terms of structural linearity as a chain $\left(\right.$ trace $\left._{i}\right)\left(\right.$ segment $\left._{i}\right)$, where $\varnothing$ is a primitive and an empty maximal projection: $\emptyset_{c}$, a trace, a non-specified co-indexed position with a specified onset: $\emptyset_{c}-C$. The asymmetry between an empty segment vs. a specified segment explains the different configurations: a sequence of $\emptyset$-C is different from a sequence of C-C. Geminates are heterosyllabic and cannot be considered a constituent. Vowel geminates $\mathrm{v}-\emptyset$ can instead in this framework be considered a harmonic constituent in the sense of Zubizarreta (1984). In fact, geminates are bounded on only one level, but they do not project. According to this view the timing unit explanation is inadequate to explain the behaviour of geminates. The OCP interdiction applies to the (here articulatory) melodies and not to positions. The OCP applies to the $\emptyset_{\mathrm{c}}-\mathrm{C}$ geminates configurations; it says that on one level two contiguous units are distinct.

The Strict CV approach (in section 4) challenges autosegmental theory in a related way, using the predictions and mechanisms of the Strict CV framework to focus on geminate integrity. The fact that geminates are never broken by vocalic epenthesis was compared with long vowels (which ought to have the same phonological behaviour, cf. Hayes 1986) and RT, NT clusters. It was shown that long vowels and geminates are not analogous when it comes to their behaviour in this regard, with long vowels subject to breaking by epenthesis while geminates never are. The explanation based on relative cue strength (Blevins 2004) was shown not to be sufficient because while RT and NT are on a scale of strength both can be split by epenthesis in certain languages, while there is no instance of geminates being broken this way. This conclusion is reflected in a novel asymmetric representation of geminates (very similar to the control by contiguity approach). The geminates are made up of a weak CV and a strong CV and the melody of the strong CV does not link to the weak CV. Consequently, in geminates (unlike long vowels) there is nothing to split and degemination can only produce singletons (with or without compensatory lengthening), or material can be only inserted to the side of the geminate (now reduced to a singleton). This asymmetry, even between long vowels and 
geminates, is shown to be reflected by the licensing conditions of Strict $\mathrm{CV}$ where both structures are essentially competing for the dependent $\mathrm{CV}$, possibly paving the way for the conclusion that melodic spreading must always come as a product of licensing. Geminates are thus analysed as being composed of a dependent, empty position and a strong, fully filled position.

We conclude with the radical claim - explored in both approaches considered here - that there is evidence, both diachronic and synchronic, that geminate consonants have an asymmetrical representation.

\section{Comments invited}

PiHPh relies on post-publication review of the papers that it publishes. If you have any comments on this piece, please add them to its comments site. You are encouraged to consult this site after reading the paper, as there may be comments from other readers there, and replies from the author. This paper's site is here:

https://doi.org/10.2218/pihph.2.2017.2588

\section{Author contact details}

Michela Russo

UMR 7023,

Structures Formelles du Langage

61 Rue Pouchet, 75017 Paris.

michela.russo@univ-paris8.fr

\section{Shanti Ulfsbjorninn}

Department of Linguistics

2 Wakefield Street London, WC1N 1PF.

s.ulfsbjorninn@ucl.ac.uk

\section{References}

Adams, James Noel. 1977. The Vulgar Latin of the letters of Claudius Terentianus. Manchester: The Pitman Press Bath (University of Manchester, Faculty of Arts Publications).

Árnason, Kristján. 2011. The phonology of Icelandic and Faroese. Oxford: Oxford University Press.

Bender, Byron W. 1968. Marshallese phonology. Oceanic Linguistics 7. 16-35.

Blevins, Juliette. 2008. Consonant epenthesis: natural and unnatural histories. In Good, Jeff (ed.), Language universals and language change, 79-107. Oxford: Oxford University Press.

Blevins, Juliette. 2004. Evolutionary phonology: the emergence of sound patterns. Cambridge: Cambridge University Press. 
Charette, Monik. 2003. Empty and Pseudo-empty Categories. In Ploch, Stefan (ed.), Living on the edge, 28 Papers in Honour of Jonathan Kaye, 465-479. Berlin/New York: Mouton de Gruyter.

ChLA 20 = Petrucci, Armando \& Jan-Olof Tjader 1982 (eds.). Chartae Latinae antiquiores: facsimile edition of the Latin charters 2 series ninth century, vol. 20: Italy 1, Cava dei Tirreni, Napoli, Vaticano. Dietikon-Zurich: Urs Graf Verlag.

ChLA $50=$ Galante, Maria (ed.). 1997. Chartae Latinae antiquiores: facsimile edition of the Latin charters 2 series ninth century. Vol. 50: Italy 22, Cava dei Tirreni. Dietikon \& Zürich: Urs Graf Verlag.

ChLA 51 and 52 = Magistrale, Francesco (ed.). 1998. Chartae Latinae antiquiores: facsimile edition of the Latin charters 2 series ninth century. Vol. 51: Italy 23. Vol. 52: Italy 24, Cava dei Tirreni. Dietikon \& Zürich: Urs Graf Verlag.

ChLA 53 = Magistrale Francesco, Cordasco Pasquale \& Clelia Gattagrisi (eds.). 1999. Chartae Latinae antiquiores: facsimile edition of the Latin charters 2 series ninth century, vol. 53: Italy 25, Montecassino, Trani, Barletta, Benevento. Dietikon-Zurich: Urs Graf Verlag.

CIL = Corpus Inscriptionum Latinarum Berlin, 1862- :

CIL IV = Inscriptiones parietariae Pompeianae Herculanenses Stabianae. Zangemeister, Karl Friedrich Wilhelm. \& Richard Schöne (eds.). 1871.

CIL V = Inscriptiones Galliae Cisalpinae Latinae. Mommsen, Theodor (ed.) :

- Pars I Inscriptiones regionis Italiae decimae. 1872 (impr.iter. 1959).

- Pars II Inscriptiones regionum Italiae undecimae et nonae. 1877.

CIL VI = Inscriptiones urbis Romae Latinae collegerunt Henzen, Wilhelm, de Rossi, Giovanni Battista, Bormann, Eugen, Huelsen, Christian Carl Friedrich \& Martin Bang (1876 and 1882).

CIL VIII = Inscriptiones Africae Latinae. Collegit Wilmanns, Gustav. Mommsen, Theodor (ed.). 1881.

CIL X = Inscriptiones Bruttiorum, Lucaniae, Campaniae, Siciliae, Sardiniae Latinae. Mommsen, Theodor (ed.). 1883.

CIL XIII = Inscriptiones trium Galliarum et Germaniarum Latinae. Hirschfeld, Otto \& Karl Zangemeister.

- Pars I, fasc. 1. Inscriptiones Aquitaniae et Ludunensis. Hirschfeld, Otto (ed.). 1904.

Charette, Monik \& Asli Göksel. 1998. Licensing Constraints and Vowel Harmony in Turkic Languages. In Cyran, Eugeniusz (ed.), Structure and interpretation: studies in phonology and syntax, 65-89. Lublin: Pase Studies and Monographs. 
Clements, G. Nick \& Samuel Jay Keyser. 1983. CV phonology: a generative theory of the syllable. Cambridge, MA: MIT Press.

Davis, Stuart. 2011. Geminates. In van Oostendorp, Marc, Colin J. Ewen, Hume, Elisabeth \& Keren Rice (eds.), The Blackwell companion to phonology, v. 2. 837-859. Malden, MA \& Oxford: Wiley Blackwell.

Davis, Stuart \& Marwa Ragheb. 2014. Geminate representation in Arabic. In Farwaneh, Samira (ed.), Perspectives on Arabic linguistics, 3-19. Philadelphia/Amsterdam: John Benjamins Co., 25.

Dell, François \& Mohamed Elmedlaoui. 1985. Syllabic consonants and syllabification in Imdlawn Tashlhiyt Berber. Journal of African Languages and Linguistics 7. 105-130.

Dell, François, Hirst, Daniel \& Jean-Roger Vergnaud (eds.). 1984. Forme sonore du langage; structure des représentations en phonologie. Paris: Hermann.

Faust, Noam. 2015. Eroded prefixes, gemination and guttural effects in Tigre: an account in CVCV phonology. Natural Language and Linguistic Theory 33(4). 1209-1234.

Faust, Noam \& Shanti Ulfsbjorninn. (to appear). Arabic stress with no moras, syllables, feet or extrametricality. Natural Language and Linguistic Theory.

Faust, Noam, Lampitelli, Nicola \& Shanti Ulfsbjorninn. (to appear in Canadian Journal of Linguistics). Italian definite article allomorphy is phonological. Also presented at: RFP 2016. University of Nice.

Goh, Yeng-seng. 1997. The Segmental phonology of Beijing Mandarin. Taipei: The Crane Publishing Co.

Guerssel, Mohamed. 1977. Constraints on phonological rules. Linguistic Analysis 3. 267-305.

Guerssel, Mohamed. 1978. A Condition on assimilation rules. Linguistic Analysis 4. 225-254.

Harris, John. 1990. Segmental complexity and phonological government. Phonology 7(2). 255-300.

Harris, John.1994. English sound structure. Oxford: Blackwell.

Hayes, Bruce.1989. Compensatory lengthening in moraic phonology. Linguistic Inquiry 20. 253-306.

Hayes, Bruce. 1986. Assimilation as spreading in Toba Batak. Linguistic Inquiry 17. 467-499.

Hayward, Dick (R.J.). 1984. The Arbore language: a first investigation; including a vocabulary. Kuschitische Sprachstudien. Band 2. Hamburg Helmut Buske.

Ingria, Robert. 1980. Compensatory lengthening as a metrical phenomenon. Linguistic Inquiry 11. 465-496. 
Kaye, Jonathan. 1995. Derivations and interfaces. In Durand, Jacques \& Francis Katamba, (eds.), Frontiers of phonology, 289-332. London \& New York: Longman.

Kaye, Jonathan \& Jean Lowenstamm. 1984. De la syllabicité. In Dell, François, Hirst, Daniel \& Jean-Roger Vergnaud (eds.), Forme sonore du langage; structure des représentations en phonologie, 123-159. Paris: Hermann.

Kaye, Jonathan, Lowenstamm, Jean \& Jean-Roger Vergnaud. 1985. The internal structure of phonological representations: a theory of Charm and Government. Phonology Yearbook 2. 305-328.

Kenstowicz, Michael.1994. Phonology in generative grammar. Oxford: Blackwell.

Kenstowicz, Michael \& Charles Pyle. 1973. On the phonological integrity of geminate clusters. In Kenstowicz, Michael \& Charles Kisseberth (eds.), Issues in phonological theory, 27-43. The Hague: Mouton.

Levin, Juliette. 1985. A metrical theory of syllabicity. PhD dissertation. MIT.

Lowenstamm, Jean. 1996. CV as the only syllable type. In Durand, Jacques \& Bernard Laks (eds.), Current trends in Phonology: models and methods, 419-44. Salford. Manchester: ESRI.

$\mathrm{R}=$ Inscriptiones Christianae Urbis Romae septimo saeculo antiquiores (1922: Vol. I; 1935: Vol. II). De Rossi, Giovanni Battista Silvagni, Angelo \& Antonio Ferrua, nova series. Roma: Libr. Pontificia.

Russo, Michela. 2011. Liaison, assimilation et redoublement syntaxique. Le sandhi consonantique du latin à l'italo-roman. In Overbeck, Anja, Schweickard, Wolfgang \& Harald Völker (eds.), Lexikon, Varietat, Philologie Romanistische Studien, Festschrift Gunter Holtus zum 65. Geburtstag, 227-242. Berlin: De Gruyter.

Russo, Michela. 2013. Constituants phonologiques et morphologies nonconcaténatives: Géminations et métaphonies dans les langues romanes. Université Toulouse 2 Le Mirail, France. HDR.

Russo, Michela. 2013a. Il raddoppiamento Sintattico dell'italiano. Tratti prosodici e struttura fonologica. In Sanchez Miret, Fernando \& Daniel Recasens (eds.), Studies in phonetics, phonology and sound change in Romance, 145-178. LINCOM Europa Studies (Phonetics series).

Russo, Michela. 2014. L'Italia dell'anno 1000: le origini del raddoppiamento sintattico nell'italiano meridionale antico e non solo. Un'analisi scrittologica. In Danler, Paul \& Christine Konecny (eds.), Dall'architettura della lingua italiana all'architettura linguistica dell'Italia. Saggi in omaggio a Heidi Siller-Runggaldier, 145-163. Frankfurt am Main: Peter Lang. 
Russo, Michela. 2016. Scriptologie galloromane et phonologie: des Mérovingiens à la dialectisation de la Gaule. Invited paper at the Séances mensuelles de la Société de Linguistique de Paris, March 2016. Paris. France. <http://www.slp-paris.com/IMG/pdf/RES-19-32016-1.pdf>.

Russo, Michela \& Joaquim Brandão De Carvalho. 2016. La quantité syllabique a-t-elle vraiment disparu en roman? Paper presented at XXVIII CILPR, July 2016. Rome. Italy.

Sauzet, Patrick. 1988. Geminates and Constituency. In Cardinaletti, Anna, Cinque, Guglielmo \& Giuliana Giusti (eds.), constituent structure: papers from the 1987 Glow conference, Venezia, annali ca' foscari. Dordrecht: Foris. 27:4. 287-330.

Sauzet, Patrick. 1994. Extensions du modèle a-linéaire en phonologie: syllabe, accent, morphologie. University of Paris VII. HDR.

Scheer, Tobias. 2004. A lateral theory of phonology. Vol 1: What is CVCV, and why should it be? Berlin: Mouton de Gruyter.

Scheer, Tobias \& Markéta Ziková. 2010. The Coda Mirror v2. Acta Linguistica Hungarica 57(4). 411-431.

Ségéral, Philippe \& Tobias Scheer. 2001. Abstractness in phonology: the case of virtual geminates. In Dziubalska-Kolaczyk, Katarzyna (ed.), Constraints and preferences, 311-337. Berlin \& New York: Mouton de Gruyter.

Steriade, Donca. 1982/1990. Greek prosodies and the nature of syllabification. PhD dissertation, MIT. Published 1990. New York: Garland.

Szigetvari, Peter. 2008. Two directions for lenition. In Brandão de Carvalho, Joaquim Scheer, Tobias \& Philippe Ségéral (eds.), Lenition and fortition, studies in generative grammar, 561-591. Berlin: Mouton de Gruyter.

$\mathrm{Tj}=$ Tjäder, Jan-Olaf. 1955. Die nichtliterarischen lateinischen Papyri Italiens aus der Zeit 445-700. Vol. I: Papyri 1-28. Lund: Gleerup.

TLIO Database $=$ Tesoro della Lingua Italiana delle Origini : www.ovi.cnr.it.

Ulfsbjorninn, Shanti. 2014. A field theory of stress: the role of empty nuclei in stress systems. PhD dissertation. SOAS - University of London.

Ulfsbjorninn, Shanti. 2017. Melody and Prosody in Strict CV Metrics. Presented at GLOW 2017, Workshop - The Interface Within - 13 March 2017. Meertens Instituut: Amsterdam.

Ulfsbjorninn, Shanti \& Mohamed Lahrouchi. 2016. The typology of the distribution of edge: the propensity for bipositionality. Papers in Historical Phonology. 1, 109-129.

Willson-Sturman, Heather. 2003. A brief introduction to Marshallese phonology. Ms. UCLA. 
$\mathrm{Xu}$, Zhuo. 2001. Phonological analysis of HONGKUI TO. PhD dissertation. Guangdong University.

Yoshida, Shohei. 1993. Licensing of Empty Nuclei: The case of Palestinian vowel harmony. The Linguistic Review. 10, 127-159.

Zubizzarreta, Maria Luisa. 1984. Accent ou Harmonie: remarques à propos d'une classe de schèmes tonaux en japonais. In Dell, François, Hirst Daniel \& Jean-Roger Vergnaud (eds.), Forme sonore du langage, 183-207. Paris: Hermann. 